\title{
The ValPar. $\mathrm{CH}$ project - Assessing the added value of ecological infrastructure in Swiss Parks
}

\author{
Emmanuel Reynard, Adrienne Grêt-Regamey \& Roger Keller
}

Keywords: Biodiversity, ecological infrastructure, ecosystem services, nature parks, values

\begin{abstract}
Ecological infrastructure (EI), which is a planned network of high-quality natural and semi-natural elements designed and managed to provide ecosystem services, has the potential to ensure rich and resilient biodiversity. Within the Action Plan for the Swiss Biodiversity Strategy of the Swiss Confederation, the pilot project known as "ValPar. CH Values of the ecological infrastructure in Swiss parks" aims to analyse the values and benefits of El at two levels: across Switzerland, and in four parks of national importance (Jurapark Aargau, and Gruyère Pays-d'Enhaut, Pfyn-Finges and Beverin nature parks). The aim is to contribute to reducing biodiversity erosion as currently observed. This objective is met by developing outputs for different stakeholders (scientific papers, recommendations, data, policy tools).
\end{abstract}

\section{Introduction}

Nature provides essential goods and services to humankind (MEA 2005; Díaz et al. 2015). These include food and drinking water production, microclimate regulation, and spiritual, aesthetic and recreational services. Nature's health, however, is degrading at rates unprecedented in human history, which exacerbates biodiversity loss and leads to significant impacts on human wellbeing. Benefits provided by nature have been conceptualized as ecosystem services (MEA 2005; Fisher et al. 2009; Serpentié et al. 2012) and further developed into the concept of Nature's Contributions to People (NCPs) (Díaz et al. 2015, 2018; Pascual et al. 2017; Kadykalo et al. 2019). NCPs can be used to describe the positive contributions (benefits) of nature to humankind but also the negative impacts (losses) people may face due to biodiversity degradation (Pascual et al. 2017). These changes are driven both by direct factors (e.g. land use and land cover, climate change, evolving technology, natural drivers) and indirect ones (e. g. demographic, economic, social-political and cultural factors). The Intergovernmental Science-Policy Platform on Biodiversity and Ecosystem Services (IPBES) has provided overwhelming evidence in its recent Global Assessment that the rate of species extinction is accelerating, with dramatic impacts on people around the world, but the report also tells us that it is not too late to make changes (IPBES 2019).

The concept of ecological infrastructure (EI) (see Grêt-Regamey et al. 2021 for a discussion) is strongly related to NCPs and is embedded in the broader concept of green infrastructure. EI is a planned network of high-quality natural and semi-natural elements designed and managed to provide ecosystem services (IPBES 2020) and to protect biodiversity (European Commission 2013). Functioning ecological infrastructure refers to the larger framework of the functions of ecosystems (Jax 2005); it includes not only structural elements (e. g., biotopes, protected areas) but also their connectivity (Grêt-Regamey et al. 2021). Factors influ- encing the functioning of the ecological infrastructure include structural elements (types and quality of land use in terms of EI, size and number of patches), functional elements (connectivity) (Fahrig 2003), as well as governance factors (Angelstam et al. 2017).

\section{The ecological infrastructure in Switzerland}

The development of EI is one of the ten strategic goals of the Swiss Biodiversity Strategy (SBS) (FOEN 2012: 54-56). EI is defined by the Swiss Federal Office for the Environment (FOEN) as a network of protected areas that contribute to safeguarding the essential services of ecosystems for society and the economy. The network consists of a core and interconnecting areas, distributed throughout the country in sufficient quality and quantity, which are also linked with valuable areas in neighbouring countries, forming the basis for a rich and resilient biodiversity (OFEV 2021).

The objective of the SBS on EI is to connect both natural and artificial (semi-natural) protected areas (Swiss National Park, biotopes, game, bird and forest reserves, Ramsar and Emerald Network sites, etc.) ecologically. In particular, the SBS aims to assess "the ecological, economic and cultural values that arise [from] or are intensified through the creation of ecological infrastructure in the parks of national importance and demonstrate the added value generated in terms of sustainable and integrated use" (FOEN 2017: 30). A functional ecological infrastructure should be effective by 2040 in Switzerland; the cantons are responsible for its planning (OFEV 2018: 85). Parks of national importance are regarded as important elements for the operationalization of the EI in Switzerland, in particular due to their function as natural laboratories (Erne 2016). The SBS objective is addressed in the Action Plan of the SBS (FOEN 2017), which encompasses 27 measures, one of them being to plan regional connectivity for ecologically valuable habitats (measure 4.3.1). This measure is being implemented through several pilot projects that aim to "valoris $[e]$ the ecological infrastructure in the parks of national importance" 


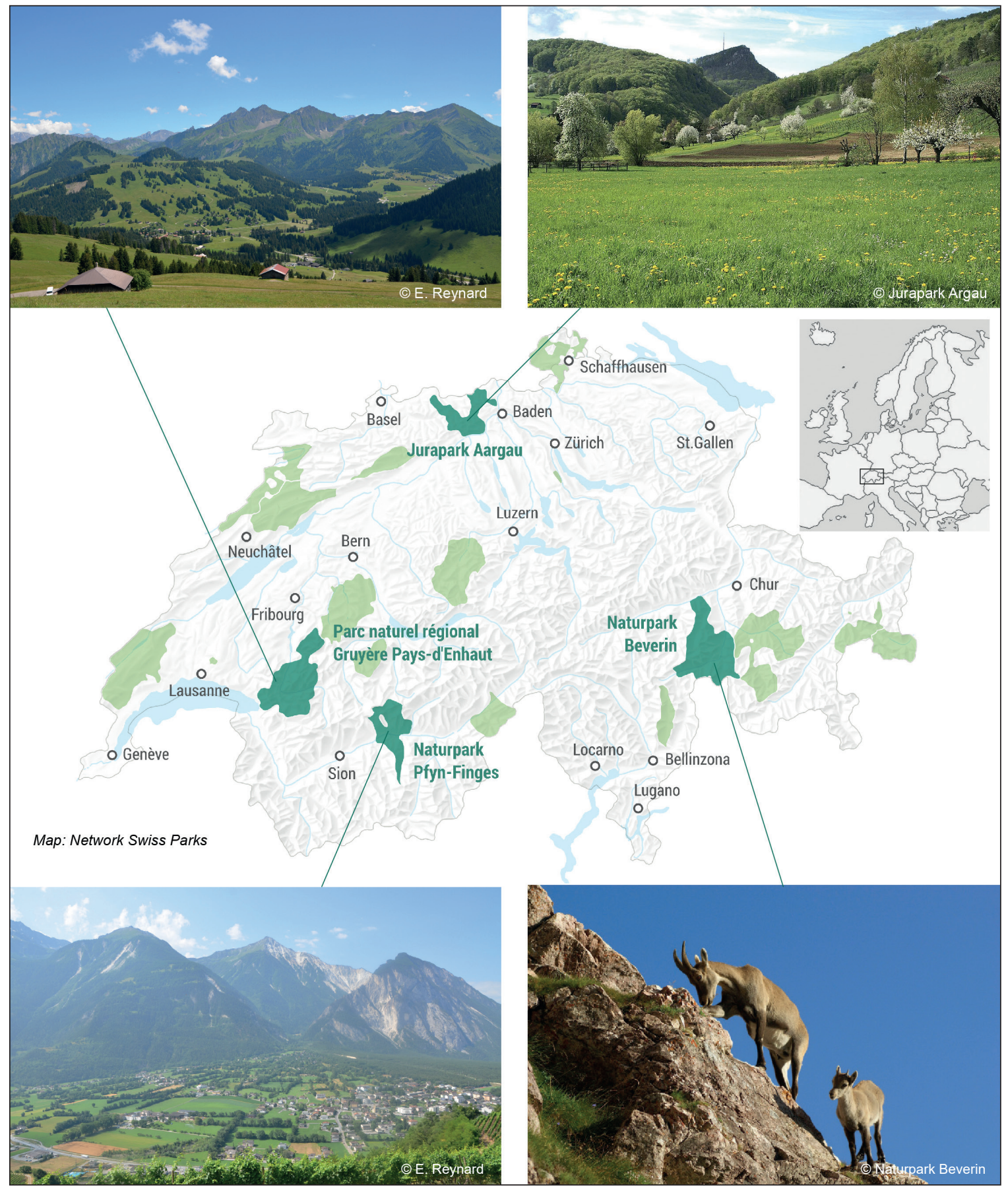

Figure 1 - Parks of national importance in Switzerland and the four parks (dark green) selected for this study.

(pilot project A1.2; FOEN 2017). From 2016 to 2019, a pilot project that involved the 16 Swiss parks and 12 cantons assessed the state of the EI in the parks and drew up various approaches to promote the EI. Several parks have published their reports (Fachgruppe Ökologische Infrastruktur 2021). Furthermore, the EI is promoted in Switzerland by the specialized Ecological Infrastructure group (ibid.), created in 2018 and hosted by the Swiss IUCN Committee. The group brings together various partners from the public and voluntary/non-profit sectors. Its objectives are to further the implementation of the concept of EI based on scientific criteria and its promotion to a broader public.
Finally, a research-oriented project was established in 2019 to tackle the question of the added value of the EI in Swiss parks.

\section{The ValPar.CH project}

ValPar.CH - Values of the ecological infrastructure in Swiss parks (ValPar.CH 2021) is a pilot project supported by the FOEN to analyse the values and benefits of the EI in the parks of national importance. It is being carried out between 2020 and 2023 by a team of more than 30 researchers from five Swiss universities (ETH Zurich, the Universities of Zurich, Lausanne and Ge- 


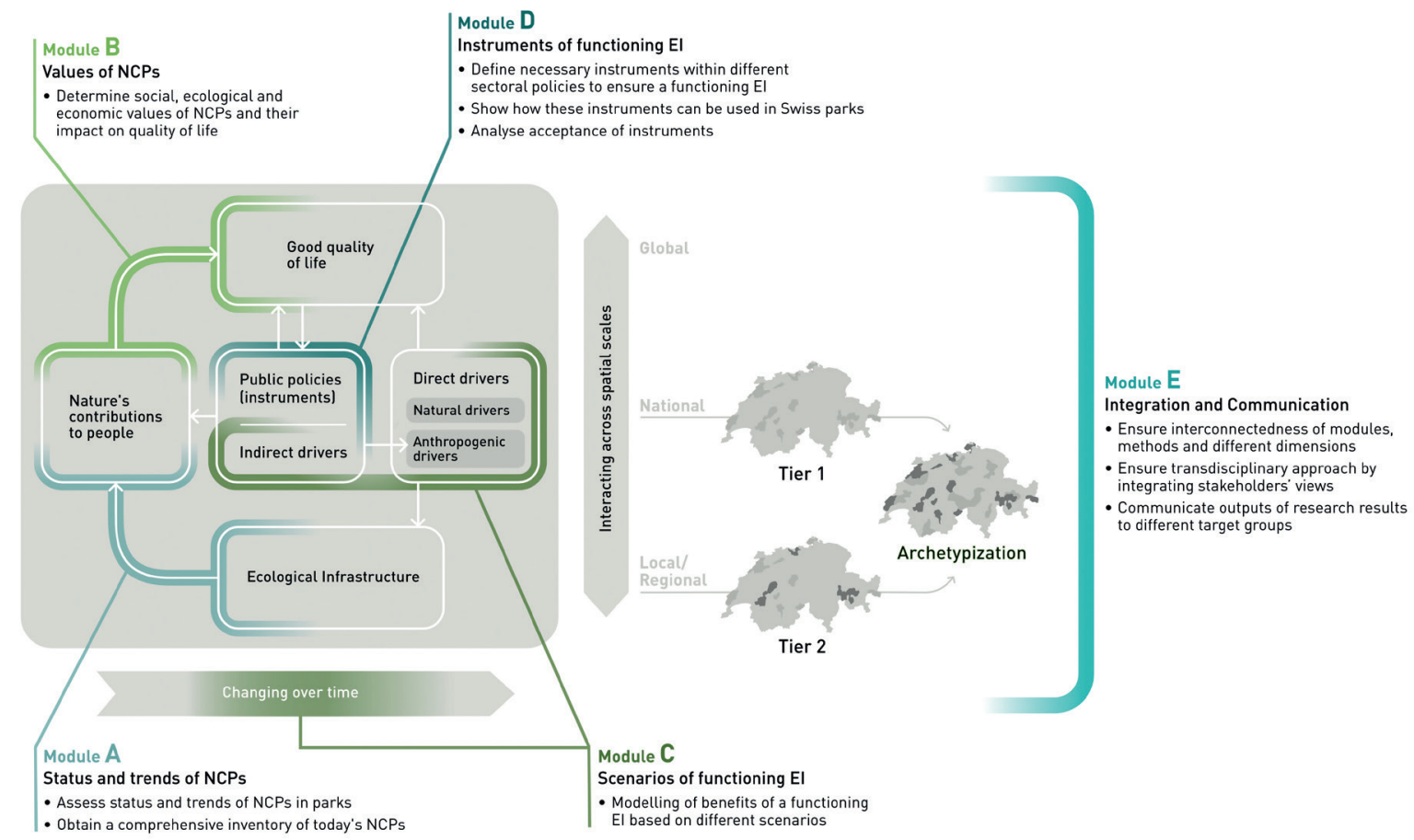

Figure 2 - Organization of the project into five modules and on two scales.

neva, and Zurich University of Applied Sciences). The project is supervised and mentored by a group from the FOEN.

The investigations are being conducted at two scales: across Switzerland, and in a selection of four Swiss parks, namely Jurapark Aargau, and Gruyère Pays-d'Enhaut, Pfyn-Finges and Beverin nature parks (Figure 1). The selection of these parks was based on geographical (natural and linguistic regions of Switzerland) and ecological criteria (coverage of the main habitat types in Switzerland), as well as data availability and the experience of the research team.

The project pursues seven main objectives:

- to determine the (added) value of a functioning ecological infrastructure for nature, the economy and society;

- to identify key areas for biodiversity and ecosystem services in parks of national importance and throughout Switzerland;

- to deepen understanding and raise awareness of the importance of ecological infrastructure as an instrument of sustainable development;

- to evaluate the willingness of the population to maintain the ecological infrastructure;

- to develop a strategy, instruments, measures and policy recommendations to improve and monitor the conditions of the ecological infrastructure in the medium term;

- to provide actor-oriented strategies for actions to maintain and strengthen the ecological infrastructure, conceptually and operationally;

- to strengthen the network of actors involved in maintaining and improving the ecological infrastructure.
The project set-up builds on the IPBES framework, which describes the interactions between nature and human societies and is organized around six major elements (Díaz et al. 2015): nature; nature's benefits to people; anthropogenic assets; institutions and governance systems, and other indirect drivers of change; direct drivers of change; and good quality of life (Figure 2). Our framework comprises five Modules:

- Module A assesses the state and trends of biodiversity and NCPs in Switzerland and in the selected parks. Quantitative maps of biodiversity and NCPs are combined with qualitative findings from Module $\mathrm{B}$ and ranked to identify the regions which are best suited to establishing a functioning EI in Switzerland. - Module B assesses the value of ecological infrastructure. The objective is to carry out a pluralistic valuation (Pascual et al. 2017) and not simply a cost-benefits economic valuation. The assessment uses economics and social science methods and considers socio-economic as well as biophysical aspects of NCPs.

- Module C elaborates various land-use development pathways under different climate and socio-economic scenarios to reach a functioning ecological infrastructure at two time horizons: 2040 and 2060. Inputs for the modelling approach are the results from Modules A and B (current state of EI and NCPs). Both monetary and non-monetary aspects of the biodiversity and NCPs are taken into account.

- Module D provides information on current and new instruments to secure a functioning EI in 2040 and 2060. It evaluates their likelihood of success as well as their political feasibility and acceptance by the relevant stakeholders. 
- Module E focuses on the integration of researchers from various disciplines (interdisciplinarity) and the participation of stakeholders (transdisciplinarity), as well as communications with society. In addition to the project management tasks, this module also conducts scientific investigations into the researchers' and stakeholders' implementation of inter- and transdisciplinarity within the project (Otero et al. 2020). More generally, it also investigates the plurality of values (intrinsic, instrumental, relational) of nature (Pascual et al. 2017), and how these values impact the assessment and implementation of EI and NCPs.

\section{An innovative project for nature parks in Switzerland}

Here, we detail the four main characteristics of the project that are of potential interest for Swiss Parks:

\section{A nested, resource-oriented approach}

Parks may be analysed as socio-ecological systems. In this project, the EI is considered as a socio-ecological system which is embedded in a park and ultimately in Switzerland. Following Ostrom's (2009) framework, we work in a nested manner, focusing on the various resource systems (e.g. water, forest, wildlife) at each level (parks, Switzerland) and identifying the various claims on the resources and how their uses are governed. Supported by a process of archetypization (i. e. a process of generalization in a series of generic types of land use), this will ensure consistency over scale and extrapolation to other parks. The cross-scale approach will also facilitate the development of a robust monitoring programme.

\section{A policy-oriented project}

The researchers - covering disciplines as varied as biology, economics, geography, political sciences, planning, etc. - collect and process a large amount of data at various scales (park and national levels), mobilizing various methods (quantitative and qualitative modelling, taken from natural, social and economic sciences). The main objective is to produce information from these data for particular stakeholders. In this, the ValPar.CH project tries to respond to the aim of the SBS Action Plan (FOEN 2017), which is the effective development of a functioning EI in Switzerland by 2040 .

\section{Inter- and transdisciplinarity at the core of the project}

Interdisciplinarity and transdisciplinarity are crucial in ValPar.CH. They are implemented at two levels:

a. Interdisciplinary cooperation between researchers: The project's organization in modules is not (mono-)disciplinary. Rather, the structure induces researchers from various disciplines to collaborate. In addition, the governance of the project is participa- tory, with a steering group representing all the research groups. Finally, self-evaluation of the interdisciplinary processes within the project is carried out following a specific protocol (Otero et al. 2020).

b. Transdisciplinary cooperation with stakeholders along three axes: (i) coordination with a sounding board composed of stakeholders involved in EI in Switzerland (FOEN, cantons, civil society, etc., including the Swiss Parks Network). This ensures the coordination with other projects on EI in Switzerland; (ii) cooperation with the managers of the four parks; (iii) co-production of knowledge with the parks' stakeholders (modules B, C, D).

\section{The science-policy continuum}

Because it is part of the SBS Action Plan (FOEN 2017) and has to answer questions formulated by the policy sector, ValPar.CH deals with the complex interactions between science and policy (van den Hove 2007). We consider that there is a continuum between science and policy (in both directions), and ValPar. $\mathrm{CH}$ will eventually have concrete repercussions on nature (biodiversity), territories (parks) and society. This means that the researchers have not only scientific responsibility, to produce high-quality scientific results, but also social responsibility, to meet the expectations of the policy sector and ultimately to help improve the quality of Switzerland's ecological infrastructure and its positive impact on nature and society.

\section{Conclusions}

ValPar.CH is one of the Swiss projects aimed at addressing the call by IPBES to reduce or even reverse the trend of biodiversity erosion currently observed. This objective is met by developing outputs for different stakeholders (scientific papers, recommendations, facts and figures, policy tools, etc.) and by translating the results not only for different stakeholder groups but also for different language regions. Finally, the project aims to contribute to the implementation of the Federal Council's SBS Action Plan, in close cooperation with other international initiatives developed by the European Union, IPBES and IUCN.

\section{Acknowledgements}

We gratefully acknowledge financial support through the Action Plan of the SBS via the Federal Office for the Environment (FOEN). We also thank our fellow members of the ValPar.CH Steering group Norman Backhaus, Raushan Bokusheva, Antoine Guisan, Daniel Kübler, Anthony Lehmann, Gretchen Walters) and all members and associated members of the ValPar.CH project team (ValPar.CH 2021) for the fruitful, supportive and interdisciplinary collaboration. Special thanks go to the stakeholders of the four study regions - the Jurapark Aargau and Gruyère Pays-d'Enhaut, Pfyn-Finges and Beverin nature parks. 


\section{References}

Angelstam, P., G. Barnes, M. Elbakidze et al. 2017. Collaborative Learning to Unlock Investments for Functional Ecological Infrastructure: Bridging Barriers in Social-Ecological Systems in South Africa. Ecosystem Services 27: 291-304. doi: 10.1016/j.ecoser.2017.04.012

Díaz, S, S. Demissew, J. Carabias et al. 2015. The IPBES conceptual framework - Connecting nature and people. Current Opinion in Environmental Sustainability 14: 1-16. doi: 10.1016/j.cosust.2014.11.002

Díaz, S, U. Pascual, M. Stenseke et al. 2018. Assessing nature's contributions to people. Science 359: 270 272. doi: 10.1126/science.aap8826

Erne, B. 2016. Schweizer Pärke als Pilotregionen. Thema Umwelt 4: 22-23.

European Commission 2013. Building a green infrastructure for Europe. Luxembourg.

Fachgruppe Ökologische Infrastruktur 2021. Den Aufbau der Ökologischen Infrastruktur unterstützen. Available at: https://www.oekologische-infrastruktur.ch/ (accessed 28/02/2021)

Fahrig, L. 2003. Effects of habitat fragmentation on biodiversity. Annual Review of Ecology, Evolution, and Systematics 34: 487-515. doi: 10.1146/annurev. ecolsys.34.011802.132419

Fisher, B., R.K. Turner \& P. Morling 2009. Defining and classifying ecosystem services for decision making. Ecological Economics 68(3): 643-653. doi: 10.1016/j. ecolecon.2008.09.014

FOEN 2012. Swiss Biodiversity Strategy. Bern.

FOEN 2017. Action Plan for the Swiss Biodiversity Strategy. Bern.

Grêt-Regamey, A., S.-E. Rabe, R. Keller, M. Cracco, J. Guntern \& J. Dupuis 2021. Arbeitspapier "Operationalisierung funktionierende Ökologische Infrastruktur". ValPar. $\mathrm{CH}$ : Werte der Ökologischen Infrastruktur in Schweizer Pärken. www.valpar.ch.

IPBES 2019. Summary for policymakers of the global assessment report on biodiversity and ecosystem services of the Intergovernmental Science-Policy Platform on Biodiversity and Ecosystem Services. Bonn. doi: 10.5281/zenodo.3553579

IPBES 2020. Glossary 'Ecological Infrastructure'. Available at: https://ipbes.net/glossary/ecologicalinfrastructure (accessed 28/02/2021)

Jax, K. 2005. Function and functioning in ecology: what does it mean. OIKOS 111(3): 641-648.

Kadykalo, A.N., M.D. López-Rodriguez, J. Ainscough et al. 2019. Disentangling 'ecosystem services' and 'nature's contributions to people'. Ecosystems and People 15(1): 269-287. doi: 10.1080/26395916.2019.1669713

MEA 2005. Ecosystems and human well-being. Synthesis, Millennium Ecosystem Assessment. New York.

OFEV 2018. Manuel sur les conventions-programmes 2020-2024 dans le domaine de l'environnement. Berne.

OFEV 2020. Infrastructure écologique. Available at: https://www.bafu.admin.ch/bafu/fr/home/ themes/biodiversite/info-specialistes/mesures- de-conservation-de-la-biodiversite/infrastructureecologique.html (accessed 28/02/2021)

Ostrom, E. 2009. A general framework for analyzing sustainability of social-ecological systems. Science 325: 419-422. doi: 10.1126/science.1172133

Otero, I., F. Darbellay, E. Reynard et al. 2020. Designing inter- and transdisciplinary research on mountains: what place for the unexpected? Mountain Research and Development 40(4): D1-D20. doi: 10.1659/ MRD-JOURNAL-D-20-00036.1

Pascual, U., P. Balvanera, S. Díaz et al. 2017. Valuing nature's contributions to people: the IPBES approach. Current Opinion in Environmental Sustainability 26: 7-16. doi: 10.1016/j.cosust.2016.12.006

Serpantié, G., P. Méral \& C. Bidaud 2012. Des bienfaits de la nature aux services écosystémiques : éléments pour l'histoire et l'interprétation d'une idée écologique. VertigO 12(3): en ligne. doi: 10.4000/vertigo.12924

ValPar.CH 2021. Available at: https://www.valpar.ch/ (accessed 28/02/2021)

van den Hove, S. 2007. Rationale for science-policy interfaces. Futures 39: 807-826.

\section{Authors}

Emmanuel Reynard - corresponding author

is a physical geographer working on systems at the interface between nature and society, such as water management, geoheritage and landscapes. Within ValPar.CH, he is a member of the project lead group and of the steering group. University of Lausanne, Institute of Geography and Sustainability and Interdisciplinary Centre for Mountain Research CIRM, Ch. de l'Institut 18, 1967 Bramois, Switzerland. E-mail: Emmanuel.reynard@unil.ch

\section{Adrienne Grêt-Regamey}

is an environmental scientist and landscape planner. Her research focuses on understanding how the interactions and/or actions of humans shape landscapes at various temporal and spatial scales, using different land-use decision models in forecasting and backcasting modes. Within ValPar.CH, she is a member of the project lead group and of the steering group. ETH Zurich, Planning of Landscape and Urban Systems PLUS, HIL H 51.3, Stefano-Franscini-Platz 5, 8093 Zürich, Switzerland. E-mail: gret@ethz.ch

\section{Roger Keller}

is a human geographer and science-policy expert focusing on services/benefits of landscape and biodiversity. Within ValPar.CH, he is project coordinator and member of the project lead group and of the steering group. University of Zurich, Institute of Geography, Unit Space, Nature and Society SNS and University Research Priority Programme on Global Change and Biodiversity URPP GCB, Winterthurerstrasse 190, 8057 Zürich, Switzerland. E-mail: roger. keller@geo.uzh.ch 